\title{
Evidence-based conservation in a changing world: lessons from waterbird individual-based models
}

\author{
SALLy Brown $(\mathbb{D} \dagger$ AND Richard A. Stillman \\ Department of Life and Environmental Sciences, Faculty of Science and Technology, Bournemouth University, Fern Barrow, Poole, \\ Dorset BH12 5BB UK
}

Citation: Brown, S., and R. A. Stillman. 2021. Evidence-based conservation in a changing world: lessons from waterbird individual-based models. Ecosphere 12(7):e03632. 10.1002/ecs2.3632

\begin{abstract}
Drivers of environmental change are causing novel combinations of pressures on ecological systems. Prediction in ecology often uses understanding of past conditions to make predictions to the future, but such an approach can breakdown when future conditions have not previously been encountered. Individual-based models (IBMs) consider ecological systems as arising from the adaptive behavior and fates of individuals and have potential to provide more reliable predictions. To demonstrate potential, we review a lineage of related IBMs addressing the effects of environmental change on waterbirds, comprising 53 case studies of 28 species in 32 sites in 9 countries, using the Drivers-Pressures-State-ImpactResponse (DPSIR) environmental management framework. Each case study comprises the predictions of an IBM on the effects of one or more drivers of environmental change on one or more bird species. Drivers exert a pressure on the environment which is represented in the IBMs as changes in either area or time available for feeding, the quality of habitat, or the energetic cost of living within an environment. Birds in the IBMs adapt to increased pressure by altering their behavioral state, defined as their location, diet, and the proportion of time spent feeding. If the birds are not able to compensate behaviorally, they suffer a physiological impact, determined by a decrease in body energy reserves, increased mortality, or decreased ability to migrate. Each case study assesses the impact of alternative drivers and potential ways to mitigate impacts to advise appropriate conservation management responses. We overview the lessons learned from the case studies and highlight the opportunities of using IBMs to inform conservation management for other species. Key findings indicate that understanding the behavioral and physiological processes that determine whether or not birds survive following a change in their environment is vital, so that mitigation measures can be better targeted. This is especially important where multiple hazards exist so that sensitivities and worse-case scenarios can be better understood. Increasing the involvement of stakeholders to help inform and shape model development is encouraged and can lead to better representation of the modeled system and wider understanding and support for the final model.
\end{abstract}

Key words: agent-based model; Drivers-Pressures-State-Impact-Response; environmental change; shorebird; wildfowl.

Received 14 July 2020; revised 26 January 2021; accepted 19 February 2021; final version received 4 May 2021. Corresponding Editor: Brooke Maslo.

Copyright: (c) 2021 The Authors. This is an open access article under the terms of the Creative Commons Attribution License, which permits use, distribution and reproduction in any medium, provided the original work is properly cited.

$\dagger$ E-mail: browns@bournemouth.ac.uk

\section{INTRODUCTION}

Environmental change, from anthropogenic and natural drivers, is putting increasing pressure on ecological systems worldwide (IPBES 2019). To prioritize responses and resources, environmental managers ideally need to anticipate how systems may change. Traditional ecological prediction methods (e.g., demographic models, habitat association models) often rely on empirical understanding of past responses as predictors of future change (e.g., previous 
survival or mortality rates, previous habitat associations). However, one difficulty with this approach is that it is often unknown whether or not the assumptions and empirical relationships upon which models are based (e.g., related to survival or mortality, habitat associations) will hold for the new environmental conditions for which predictions are required (Evans 2012, Stillman et al. 2015a). This is particularly so in complex ecological environments. Furthermore, when change is novel (i.e., has not occurred before), there may be no suitable existing data (e.g., on survival or mortality, habitat associations) that can be used as the basis of predictions (Stillman et al. 2015a).

Individual-based models (IBMs; also termed agent-based models) have potential to provide more reliable predictions by simulating the links from the environment, through individuals, to populations (Grimm and Railsback 2005). Individual-based models consider ecological populations as having properties that arise from the behavior and fates of the individuals that comprise these populations and can, critically, incorporate adaptive decision-making of individuals (Grimm and Railsback 2005). This assumes that given a range of potential choices, animals will act in ways that maximize their chances of survival and reproduction (i.e., their fitness). This mimics the way in which real animals are expected to behave, as it is assumed that evolution through natural selection has led to behavior that maximizes fitness (Stillman et al. 2015a). The benefit of incorporating adaptive behavior is that the basis of predictions - fitness maximizationis more likely to maintain its predictive power to new environments than the empirical relationships on which more traditional methods are based (Stillman et al. 2015a). In addition, IBMs have the ability to predict the effect of novel environmental change that has not previously occurred on a site, as their predictions are not based on empirical relationships derived from past conditions.

Although IBMs are used less frequently than traditional approaches due to knowledge, experience and expertise, they have been more widely used to support the evidence base for conservation management for waterbirds (e.g., shorebirds, wildfowl; Stillman and Goss-Custard 2010). In the absence of such evidence, anthropogenic changes to the environment have often proceeded on the basis of the precautionary principle, meaning that activities may be banned even if they have no adverse effect on the birds. Equally, damaging activities may be allowed to continue. For example, in The Wash (Atkinson et al. 2003) and Wadden Sea (van Roomen et al. 2005), high mortality rates of shellfish-consuming birds occurred as a result of overfishing of their shellfish food supply as the exact requirements of the birds were underestimated. Insights derived from IBMs have since supported a policy change that increases the amount of shellfish reserved for the birds (GossCustard and Stillman 2008). Despite widespread successful application to waterbirds, there has not been an overview of how IBMs align with conservation management for these species.

In this paper, we review all post-2000 case studies of related waterbird IBMs of different sites, bird species, and issues, to demonstrate, in the context of the Drivers-Pressures-StateImpact-Response (DPSIR) environmental management framework (Gabrielsen and Bosch 2003), and how predictions from IBMs have been used in conservation management. We initially describe these IBMs and the DPSIR framework. We then overview a range of lessons learned from the case studies, aligned to different parts of the DPSIR framework. Finally, in the light of the lessons, we propose ways in which IBMs could be applied and developed more efficiently, with the aim of encouraging the wider use of IBMs to support the evidence base for conservation management.

\section{Applying the DPSIR Framework to WATERBIRD IBMS}

\section{Waterbird IBMs}

The waterbird IBMs considered here comprise a lineage of related models, dating from the early 1990s, with a diversification of applications since 2000. The main purpose of these models is to predict how variation in environmental conditions affects the ability of birds to gain enough food to maintain good condition, migrate successfully from a site, and/or survive the non-breeding season. They represent part of the annual cycle of these birds and are not intended to represent population dynamics over a longer period of time. The advantage of focusing on a shorter time 
period is that details of the mechanisms through which environmental conditions affect the birds can be more clearly understood and tested. Furthermore, in many cases, conservation issues for these species can be addressed by understanding the consequences of environmental change during critical periods of the annual cycle.

The earliest models were for Eurasian Oystercatcher Haematopus ostralegus feeding on Blue Mussel Mytilus edulis on the Exe estuary, UK. These were based on a long-term (1976-1990) study of the birds and their food supplies. Three versions of the Exe Estuary model were developed up to 2000 (Goss-Custard et al. 1995a,b, Clarke and Goss-Custard 1996, Stillman et al. 2000). In parallel, IBMs for brent goose (Branta bernicla) and barnacle goose (Branta leucopsis) were developed (Pettifor et al. 2000). A common feature of these early models was that their software was highly specific to particular systems, meaning that they could not easily be applied to another species or site without extensive new data and recoding of the model software. To overcome these issues, a new more flexible model, MORPH, was developed in the 2000s (Stillman 2008b) that could be applied to a wide variety of systems without needing to be recoded. Together with progress in predicting rates at which birds feed (Stillman et al. 2002, Goss-Custard et al. 2006c), it meant that a model's creation time decreased from years to months, and the need for external input data to differentiate between sites also greatly decreased (Stillman and Goss-Custard 2010).

MORPH and its predecessors define the modeled environment through patches of habitat, food resources, and foragers. They simulate changes in space, time, and environmental conditions. The models account for the effect of food abundance and quality on the rate at which animals can consume food, and also the potentially negative effect of competitors, through competition over food, on the rate of feeding. Animals attempt to meet their daily energy requirements by feeding in the locations and at the times that maximize fitness. Animals adjust the proportion of time for which they feed to meet their energy requirements. Model animals that are not able to meet their requirements draw on their energy reserves. Thereafter, if animals continue to lose energy, they will die of starvation (Stillman 2008b). Although starvation is the main source of mortality in the models discussed here, MORPH can also incorporate other sources of mortality, for example, from predation, hunting, or accidents.

\section{Drivers-Pressures-State-Impact-Response framework}

Drivers-Pressures-State-Impact-Response is widely used in environmental management (Gabrielsen and Bosch 2003) and was designed to communicate outcomes of environmental assessments. It describes a causality chain of outcomes in a system through an interactive and reactive chain of events. This stems from a driver which exerts a pressure and changes the state of the environment and its actors. This produces an impact, which results in a response. Indicators in environmental management frameworks were developed from the Organisation for Economic Cooperation and Development (OECD) and by Rapport and Friend, as described in an Environmental Protection Agency (1995) report and Gabrielsen and Bosch (2003). This used the "Pressure State Response" framework, with further additions of the identification of pressures. These were identified into those that were of human and non-human origins and could be subdivided into underlying, direct, and indirect pressures. In turn, this supported how environmental information systems are used to support the assessment of environmental problems, including changes, causes, and scenarios for future impacts. It noted the effects of these changes on the environmental systems. Later impacts were included, and also fundamental drivers. The Drivers-Pressures-State ImpactResponse framework has been widely applied, including with minor alterations in the components of the framework, as described in Patrício et al. (2016).

Fig. 1 illustrates the links between the drivers and subsequent pressure (on the environment), state (of the birds), impact (on the birds), and response (methods of how to reduce impacts through changes in the drivers). A reduction in habitat area, time, or quality or an increase in energy cost all tend to increase the difficulty that birds have in meeting their energy requirements. Model birds can react to these pressures by changing their state, measured as their location, diet (both determined by the birds' fitness- 


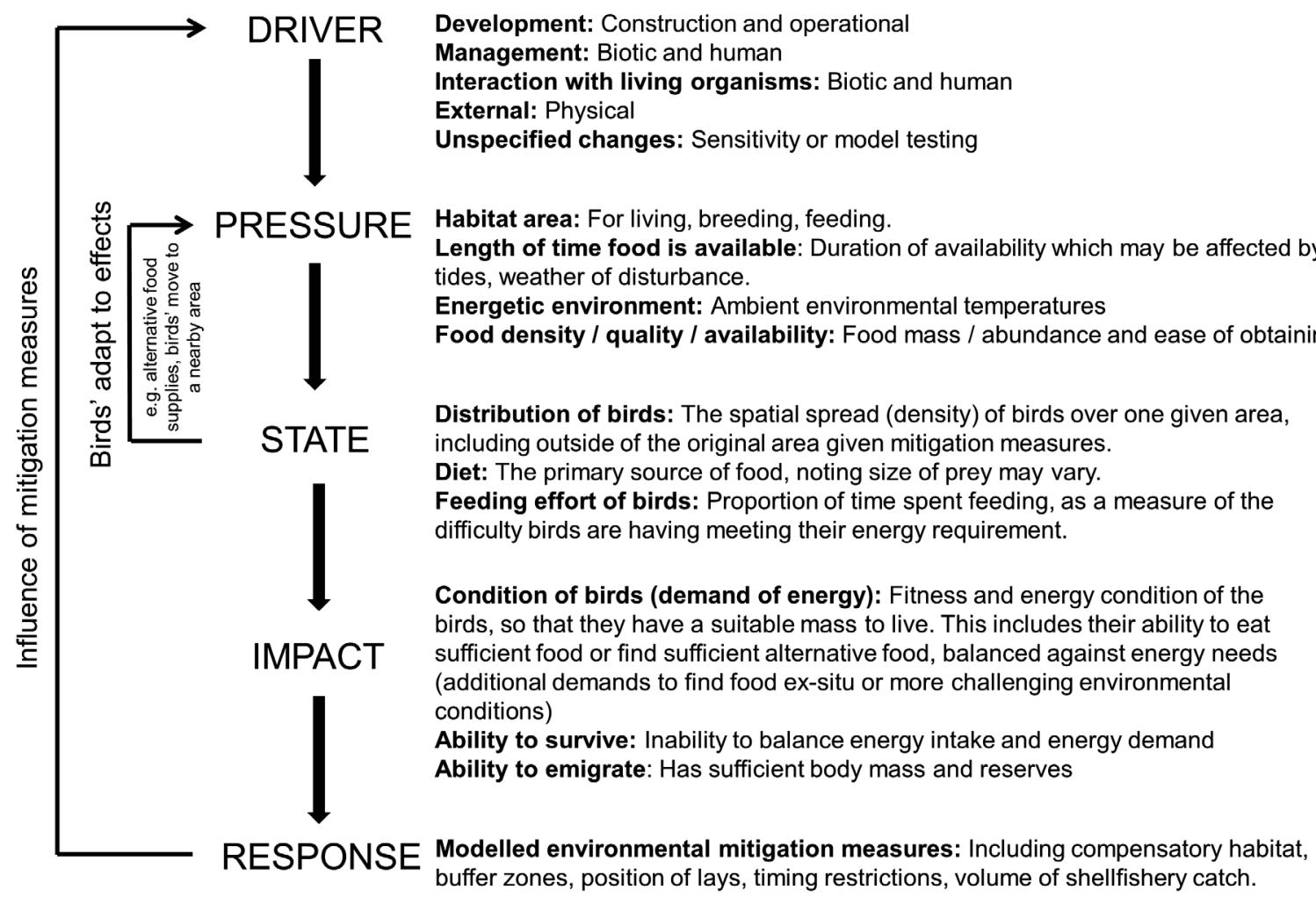

Fig. 1. Application of the DPSIR framework to the waterbird case studies. Drivers of five different types (varying between case studies) exerted pressure on the environment by changing the area and time available for feeding, the density/quality/availability of food, and/or the energetic cost of living in an environment. Model birds within IBMs attempted to compensate for these pressures by changing their behavioral state (i.e., location, diet, and proportion of time spent feeding). Model birds that could not compensate for the pressures suffered a physiological impact (i.e., loss of body condition, reduced survival, and/or ability to migrate). The predicted impact of drivers on the birds can be used to inform the environmental management response to influence or mitigate the effects of drivers.

maximizing decisions), and proportion of time spent feeding (determined by the time required to meet energy needs). Where a threshold is reached when birds cannot meet their energy demands even by feeding for all available time, this impacts their physiology, and thus their potential to survive or migrate. Each case study predicted the conditions under which drivers and associated pressures led to an impact on the birds, to inform the appropriate responses to reduce these impacts.

\section{Lessons From the Waterbird Case Studies}

Since 2000, MORPH and its predecessors have been applied to 53 case studies: thirty-four used
MORPH and 17 its predecessors. These spanned 32 locations in 9 countries (Fig. 2) and 28 bird species (see Appendix S1 and Appendix S2). This section overviews the lessons learned from these case studies.

\section{IBMs as an appropriate approach for modeling waterbirds}

Individual-based models require parameters to be measured at different levels of the organization within a system (e.g., individual and population), with the complexity of an IBM being determined by the complexity of the system being modeled. Waterbird systems are relatively simple, easily observed systems, as they are essentially two dimensional with few barriers to 


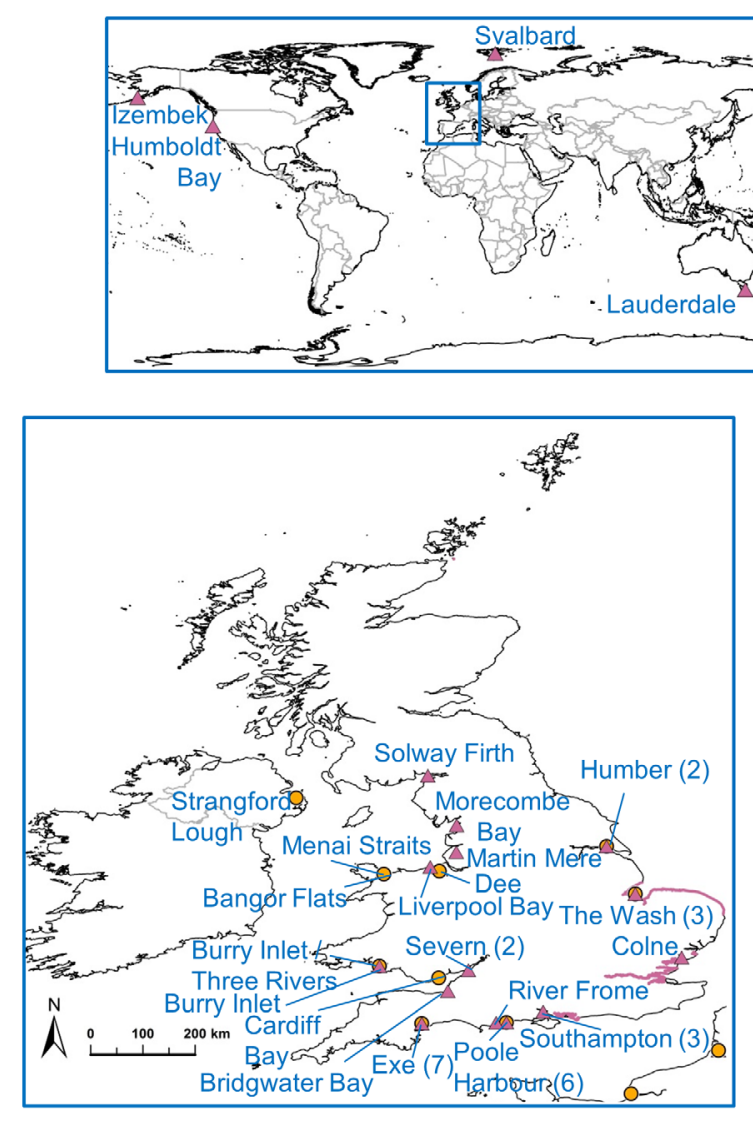

Predictive ecology (number of case studies in brackets)

Single case studies using MORPH (and its predecessors where used)

— Multiple case studies using MORPH

Single case studies using MORPH's predecessor

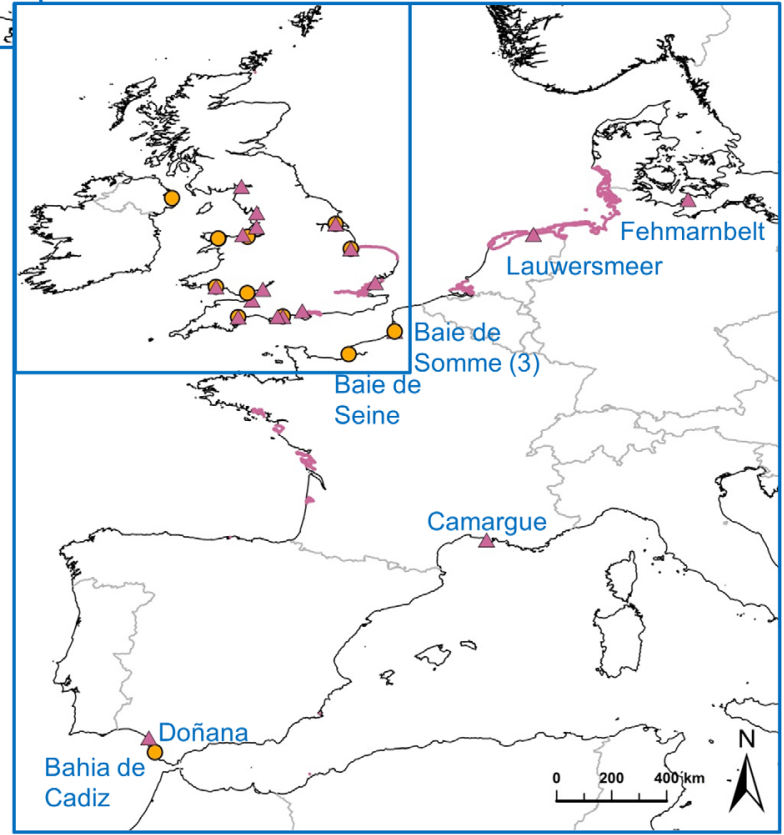

Fig. 2. Location of the waterbird case study sites. The IBM used within each case study was either MORPH (triangles) or predecessor of MORPH (circles). All case studies were of single sites except for the Denmark to Spain and Denmark to Svalbard case studies which encompassed multiple sites. In these cases, each site included in the case study is shown. The numbers next to some sites represent the number of case studies within the site (sites without a number have one associated case study).

the direct observation of the birds. In waterbird systems, the food supply is relatively static, with surface or sediment-dwelling invertebrates (e.g., Polychaeta, Mollusca, and/or Crustacea in Bahia de Cadiz shorebirds, Stillman et al. 2005a; Baie de Seine shorebirds, dit Durell et al. 2005; Camargue Greater Flamingo Phoenicopterus roseus, Deville 2013; Lauderdale Pied Oystercatcher Haematopus longirostris, Atkinson and Stillman 2008) or vegetation (e.g., Gramineae, Ulva spp. and/or Zostera spp. in Western Europe brent goose Branta bernicla, Stillman et al. 2005a; Martin Mere pink-footed goose Anser brachyrhynchus, Bournemouth University and Wildfowl and Wetlands Trust 2018; Izembek Lagoon Black Brant
Branta bernicla nigricans, Stillman et al. 2021; Humboldt Bay Black Brant, Stillman et al. 2015b; River Frome Mute Swan Cygnus olor, Wood and Stillman 2014; Exe Estuary - C Brent Geese, Stillman et al. 2005c). Furthermore, environmental management for these species often can be usefully informed by answering relatively shortterm questions spanning a fraction of the lifespan of the species. For example, what is the effect of a new development on the number of individuals that will survive the non-breeding season? New technology will play an increasingly important role in the measurement of ecological data (e.g., through miniaturization of tags to track animals and remote sensing to measure wildlife and food 
distribution). This means that the parameterization and testing of IBMs will become more straightforward, but the lesson from the waterbird case studies is that directing effort toward similar types of, relatively simple, system could be a profitable way of increasing the use of IBMs to inform environmental management.

\section{Waterbird IBMs in relation to the DPSIR framework}

Individual-based models were often required due to changing drivers in a coastal or wetland site. The drivers could have been a potential threat to a site or a network of sites (Table 1). Four families of drivers were identified:

1. Development during construction (e.g., Fehmarn Belt tunnel; FEBI 2013a,b) and operation (e.g., Severn Estuary-A tidal barrage; Bournemouth University 2010; Liverpool Bay wind farm, Kaiser et al. 2005; Cardiff Bay tidal lagoon, Goss-Custard et al. 2006a; Bridgwater Bay nuclear power station, Garcia et al. 2016; Southampton Water-A port development, Wood 2007).
2. Management of the biotic (e.g., Baie de Somme-A and C shellfishing; GossCustard et al. 2004, dit Durell et al. 2008; Dee Estuary shellfishing, West and McGrorty 2003, Stillman and Wood 2013b; Solway Firth shellfishing, Stillman 2008a, Stillman and Wood 2013a; Exe Estuary-E and G shellfishing, Stillman et al. 2014, Goss-Custard et al. 2019) and physical environment (e.g., Baie de Cadiz sea-level rise, Stillman et al. 2005a).

3. Interaction with living organisms, including humans (e.g., Southampton Water-B recreation, Stillman et al. 2012; Baie de SommeB human activities, Goss-Custard et al. 2006b) and other biota (e.g., Poole Harbour -B Manila Clam Venerupis philippinarum, Caldow et al. 2007; Colne Estuary Pacific Oyster Crassostrea gigas, Herbert et al. 2018).

4. External physical changes (e.g., extreme weather in Izembek Lagoon, Stillman et al. 2021; and Exe Estuary-D, Stillman et al. 2005a,c, dit Durell 2007; or sea-level rise in Humber Estuary-A and B, Stillman et al. 2005b, Bowgen 2016).

Table 1. Types of driver included within the case studies.

\begin{tabular}{|c|c|c|c|}
\hline Driver & $\begin{array}{c}\text { Driver } \\
\text { sub-category }\end{array}$ & Examples & How IBMs can assess potential impact of driver \\
\hline Development & $\begin{array}{l}\text { Built (during } \\
\text { construction) }\end{array}$ & Buildings, transport, energy & $\begin{array}{l}\text { Ranking alternative proposals in terms of their impact on } \\
\text { birds } \\
\text { Assessing the effectiveness of alternative including } \\
\text { mitigation measures }\end{array}$ \\
\hline Development & $\begin{array}{l}\text { Built (when } \\
\text { operational) }\end{array}$ & Buildings, transport, energy & $\begin{array}{l}\text { Ranking alternative proposals in terms of their impact on } \\
\text { birds } \\
\text { Assessing the effectiveness of alternative including } \\
\text { mitigation measures }\end{array}$ \\
\hline Management & Biotic & $\begin{array}{l}\text { Agriculture, aquaculture, } \\
\text { shellfishing }\end{array}$ & $\begin{array}{l}\text { Determining the amount of food that needs to be reserved } \\
\text { for the birds } \\
\text { Assessing the impact of alternative ways of managing the } \\
\text { harvesting of resources, including mitigation and/or } \\
\text { adaptation through regulations }\end{array}$ \\
\hline Management & Physical & $\begin{array}{l}\text { Managed shoreline change, } \\
\text { water level change }\end{array}$ & $\begin{array}{l}\text { Determining the required habitat area and food } \\
\text { availability, and testing mitigation and/or adaptation } \\
\text { measures through policy }\end{array}$ \\
\hline $\begin{array}{l}\text { Interaction } \\
\text { with living } \\
\text { organisms }\end{array}$ & Biotic & $\begin{array}{l}\text { Invasive species, living } \\
\text { organisms }\end{array}$ & $\begin{array}{l}\text { Testing new environmental conditions or regulations to } \\
\text { restrict activity }\end{array}$ \\
\hline $\begin{array}{l}\text { Interaction } \\
\text { with living } \\
\text { organisms }\end{array}$ & Human & Hunting, recreation & $\begin{array}{l}\text { Testing new environmental conditions or regulations to } \\
\text { restrict activity }\end{array}$ \\
\hline External & Physical & $\begin{array}{l}\text { Sea-level rise, sediment } \\
\text { change, extreme weather }\end{array}$ & $\begin{array}{l}\text { Testing scenarios of largely uncontrollable change and } \\
\text { possible adaptation measures }\end{array}$ \\
\hline Unspecified & $\begin{array}{l}\text { Sensitivity tests } \\
\text { with no clear } \\
\text { driver }\end{array}$ & $\begin{array}{l}\text { A pressure of a reduction of } \\
\text { habitat or change in prey } \\
\text { quality }\end{array}$ & $\begin{array}{l}\text { Testing model limits and valid of sensitivity tests relating } \\
\text { to impact on the birds }\end{array}$ \\
\hline
\end{tabular}


A fifth category of unspecified was included if the cause of a pressure was unclear or if the pressure was included as part of a sensitivity test (e.g., migration in Svalbard, Duriez et al. 2009; unspecified changes to habitat area and availability in Southampton Water-C, Bowgen 2016; and Poole Harbour-C, Ross 2013).

Interactions between drivers and subsequent pressures are illustrated in Fig. 3. Use of an IBM was essential in these cases as the potential threat had not normally been encountered on the site previously (e.g., the driver was novel or more extreme than historically), and so traditional methods of ecological prediction could not be used as there were no background data on which to base predictions. Prediction using IBMs based on the fitnessmaximizing decisions of individuals was therefore an appropriate approach to assess the potential impacts of these usually novel drivers on waterbirds.

Incorporating the effect of multiple pressures resulting from one or more drivers is relatively straightforward in IBMs. This is because these drivers and pressures are converted into a set of standard ways in which the individuals within IBMs can be affected. In the case of the waterbird IBMs, all drivers exerted pressures through changing the time and area available for feeding and the quality of food. Only external physical changes (represented by decreasing temperatures) affected the energetic environment. Note that changes in the energetic environment are not to be confused by the birds' energetic needs, which can be easily affected by the aforementioned drivers.

Birds responded to pressures in standard ways, on the basis of fitness-maximizing decisions expected to hold for novel conditions, by adjusting their diet, location (i.e., distribution), and/or proportion of time spent feeding (Fig. 4). In contrast, more traditional methods of ecological prediction would require historical data incorporating variation in the pressures applied by multiple drivers, which would be typically unavailable if drivers are novel or more extreme than previously experienced on a site. Individual-based models are therefore a particularly suitable approach for predicting the impact of multiple in-combination effects on wildlife.

\section{Incorporating pressures within waterbird IBMs}

Individual-based model simulations were run incorporating either (1) the presence or absence of multiple pressures or (2) the magnitude of a pressure. Modeled birds within the IBMs altered their behavioral state (diet, location, proportion of time feeding) using adaptive decision-making to minimize any impact of the pressures on their body condition, migration, or survival probability (Fig. 5). A predicted impact occurred when the model birds were not able to compensate for increased pressures by changing their behavioral state, in which case either body condition, migration probability, and/or survival probability decreased. For example, the presence of some proposed tidal barrages (presence/absence drivers) in the Severn Estuary-A was predicted to reduce the number of birds that could be supported as the area of feeding habitat and time for which this habitat was available were reduced. An increasing pressure of higher water levels (magnitude driver) above a threshold level was predicted in Lauwersmeer (Nolet et al. 2016) and Camargue (Deville 2013), as Bewick's Swan Cygnus columbianus bewickii and Greater Flamingo, respectively, were able to access a lower proportion of their food resources as water levels rose.

\section{Incorporating concurrent drivers within waterbird IBMs}

Several case studies demonstrated that impacts were more likely to occur at times when environmental conditions meant that birds were particularly vulnerable, indicating that multiple and combinations of drivers were important (Fig. 5). This included biotic management and weather conditions (e.g., Burry Inlet; Stillman et al. 2001, West et al. 2003a), food availability and weather conditions (e.g., Izembek Lagoon; Stillman et al. 2021), and human activity and food availability (e.g., Baie de Somme-B; Goss-Custard et al. 2006b).

The main environmental factor that made birds especially vulnerable was low temperature, which increased the daily energy requirements of the birds (e.g., Poole Harbour-A; Stillman et al. 2005c, dit Durell et al. 2006) and could reduce food availability (e.g., due to frozen fields in Exe Estuary-A; Stillman et al. 2000, 2001; or sea ice in Izembek Lagoon, Stillman et al. 2021), 

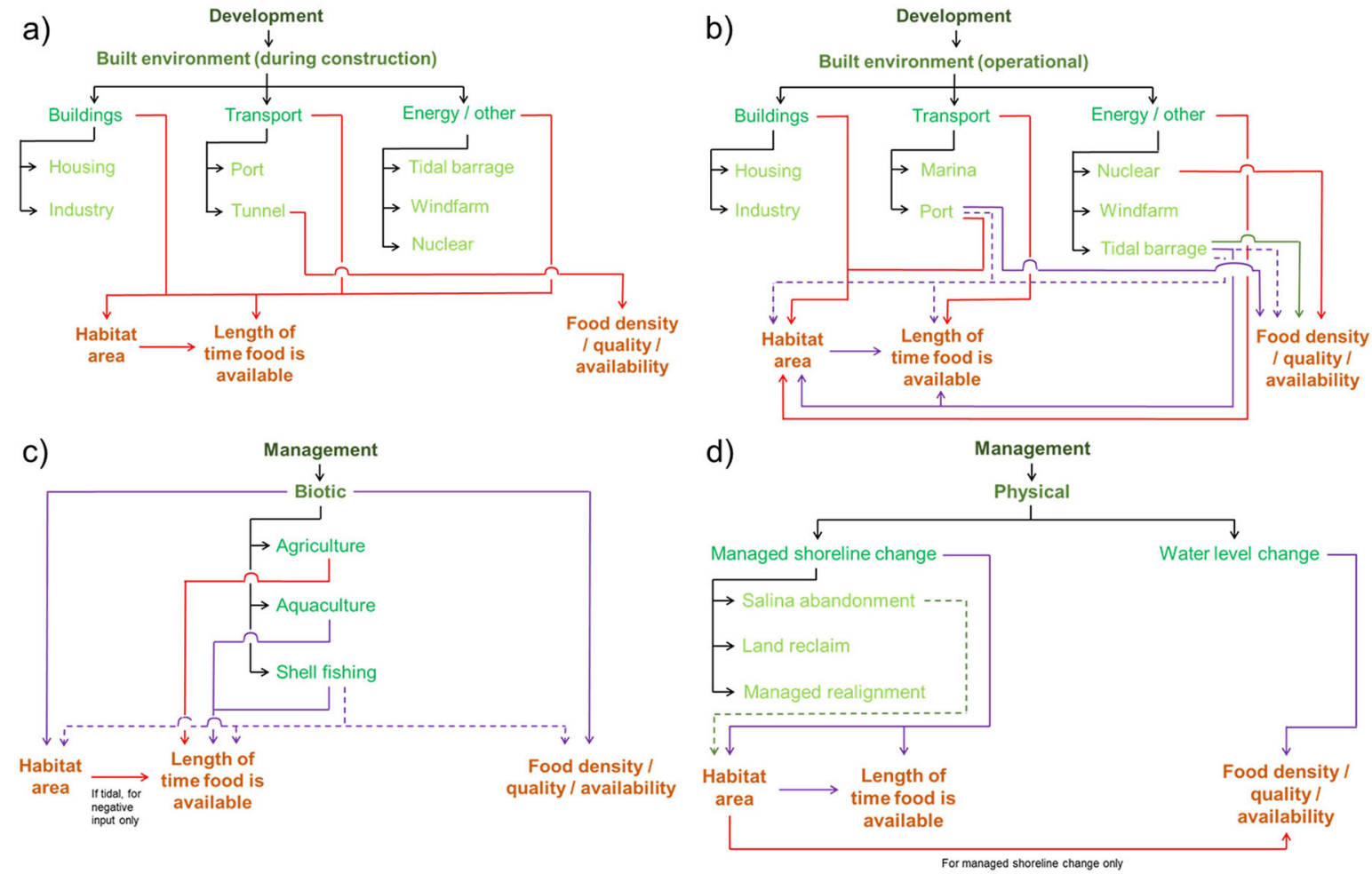

e)

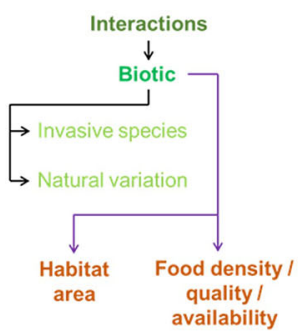

g)

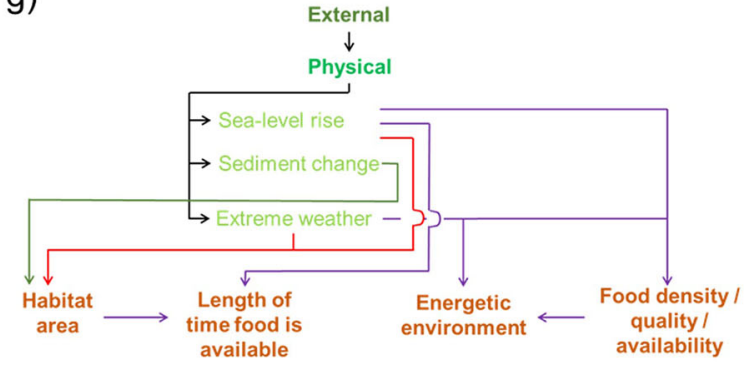

f)

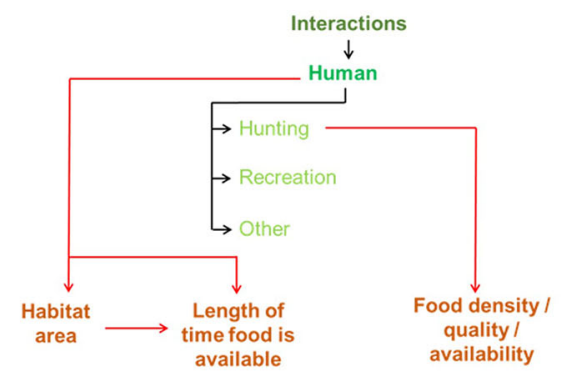

Fig. 3. Alternative pathways between drivers and pressures within the waterbird case studies. Each figure (a-g) represents the pathway stemming from a different type of driver. Specific types of driver included in the case studies are then listed. The arrows from the drivers show the range of ways in which different types of driver influenced pressures. 


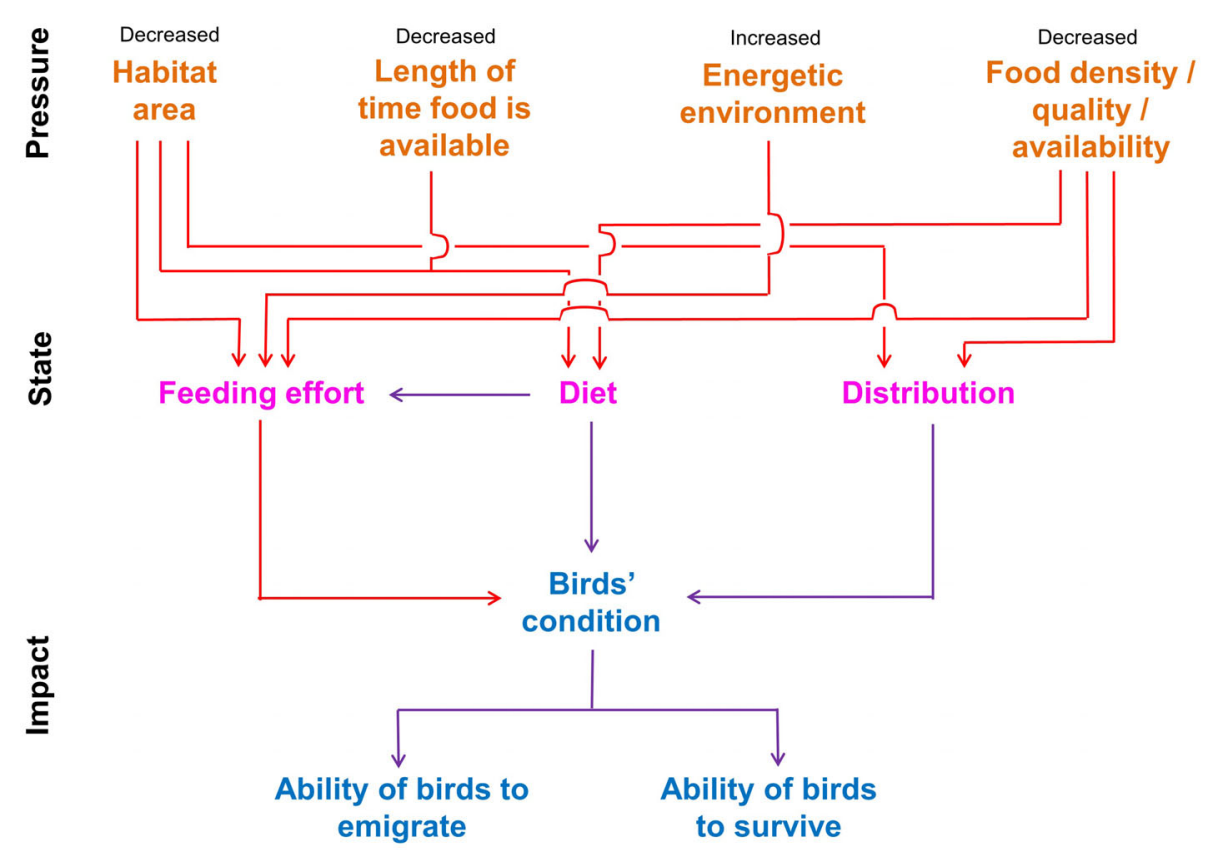

Fig. 4. Pathways between pressures, states, and impacts with the waterbird case studies. The arrows from the pressures show the range of ways in which different types of pressure influenced the behavioral states of the birds. The arrows from the states show the link between changes in state, through the body condition of the birds to ability to emigrate or survive.

both of which reduced the ability of the birds to consume enough food to compensate for a driver. In Baie de Somme-B (Goss-Custard et al. 2006b), birds were predicted to be more vulnerable to increased disturbance from human activity at times when food was less abundant and/or when temperature was lower, as birds were less able to compensate for the time and energy cost of disturbance. Hence, the additional pressure from cold weather could increase the impact of an anthropogenic driver.

Often, multiple drivers (as described in Fig. 5) resulted in a common pressure. For instance, in Poole Harbour-F (Collop 2016), disturbance from increased human activity was only predicted to negatively impact on the birds if associated with a decline in site food quality. In Humber Estuary-A (Stillman et al. 2005b), the predicted impact on birds of habitat loss was greater when food was less abundant, as a smaller habitat area is required when food is more abundant. In Baie de Cadiz (Stillman et al. 2005a), both salina abandonment and aquaculture intensification resulted in a change in habitat area.
The additive effect of multiple drivers and the increased vulnerability of animals under particular environmental conditions are likely to apply to animal populations in general, and so environmental management will need to account for such in-combination effects. Individual-based models are typically better able to integrate multiple drivers and pressures than traditional ecological model, especially when changes are novel, and so could be an especially valuable tool in such conditions.

\section{Determining why waterbirds are impacted by pressures}

The impacts predicted by IBMs can be considered as what could potentially happen when increasing pressure is applied to a system (i.e., the results of change in that specific environment on bird condition or survival), while the predicted changes in behavioral states can be considered as why this happens (i.e., the underlying reasons why condition or survival were affected). Understanding the conditions under which behavioral changes in birds are unable to compensate for increasing pressure on the 


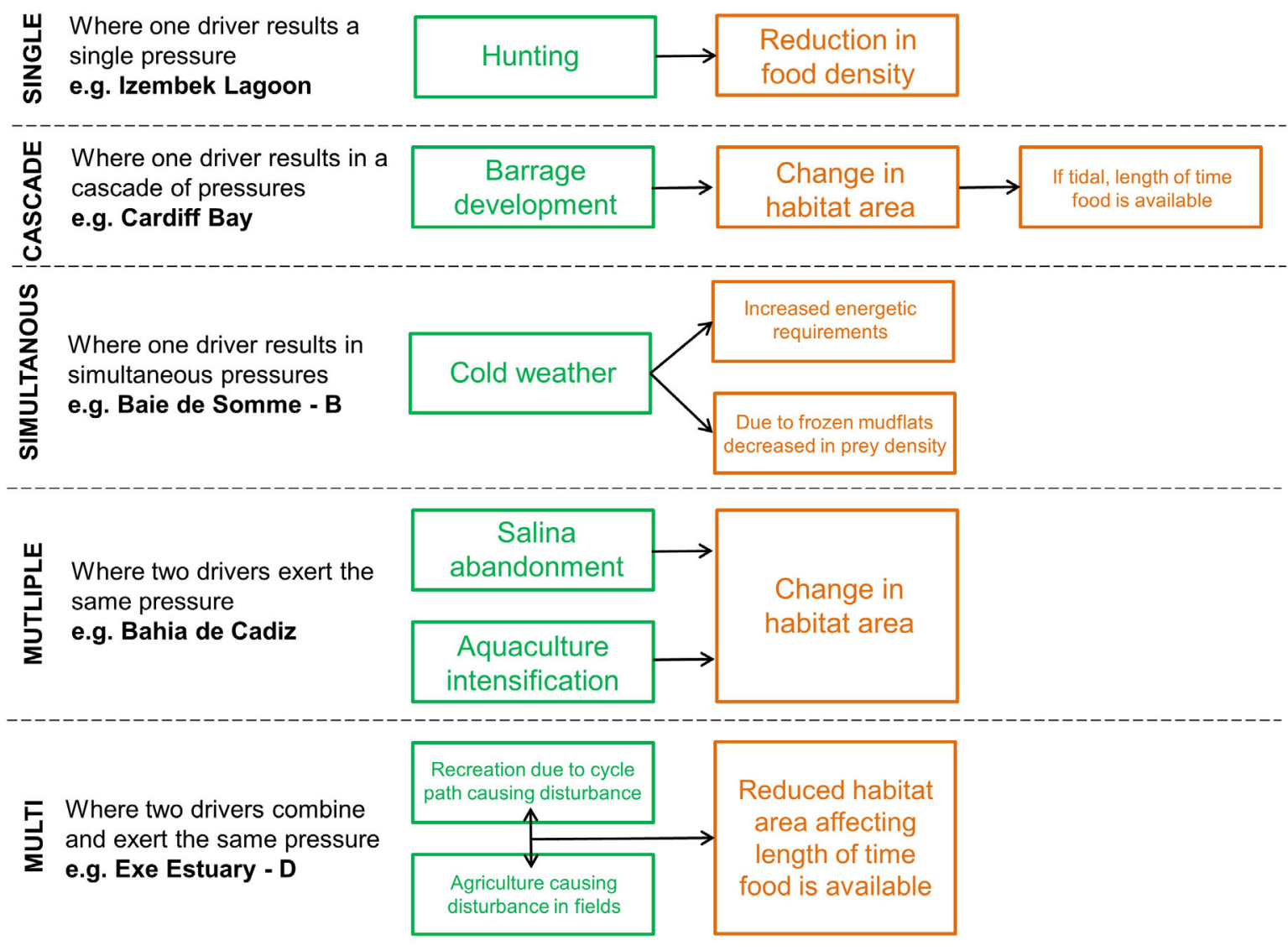

Fig. 5. Alternative pathways through which drivers can lead to pressures in the waterbird case studies.

environment could potentially provide valuable insights into why particular types of driver may adversely affect the birds and what may be the most appropriate types of mitigation to offset any negative effects (Fig. 1). Individual-based models allowed these conditions to be tested in advance, so that appropriate mitigation measures could be considered, proactively within the environment or through predicting the response of the birds. For instance, Burry Inlet (Stillman et al. 2001, West et al. 2003b), Donana National Park (Toral et al. 2012), Exe EstuaryA (Stillman et al. 2000, Stillman et al. 2001) and F (Collop 2016), Humber Estuary-B (Bowgen 2016), Poole Harbour-D (Bowgen et al. 2015, Bowgen 2016) and E (Clarke 2018), Severn Estuary-B (Bowgen 2016), Southampton Water-B (Stillman et al. 2012), Western Europe (Stillman et al. 2005a), and Martin Mere (Bournemouth University and Wildfowl and Wetlands Trust
2018) all showed the predicted effects of pressures on the behavioral states of the birds, hence the ways in which the birds attempted to compensate for the increased pressure. Changes in behavioral state included changes in diets and feeding location to compensate for loss of preferred food or feeding habitat and increases in the proportion of time spent feeding to compensate for deteriorating feeding conditions. In Burry Inlet/Three Rivers (Stillman 2008c, Stillman et al. 2010), Eurasian Oystercatcher Haematopus ostralegus increased their time spent feeding and changed their diet and location, to attempt to compensate for a reduction in the abundance of their shellfish prey. In Western Europe (Stillman et al. 2005a), loss of terrestrial food (that was present throughout the nonbreeding season) was predicted to more adversely affect brent goose than a loss in intertidal food (that was present just at the start of 
the season). This happened because birds could switch to terrestrial food if intertidal food was lost at the start of the season, but did not have an alternative to terrestrial food later in the season. These examples were exceptions, however, and case studies typically did not present changes in the behavioral states of model birds, but instead focused primarily on the link between pressures and impacts. A lesson here is that all steps in the chain from pressures to impacts should be presented to more completely explain not only what happens when increasing pressure is applied, but also why this happens. This can help the type, form, and timing of conservation measures.

\section{Using IBMs More EfFiciently}

\section{Inclusion of stakeholders}

The relative complexity of IBMs means that it is especially important for stakeholders to be involved in as much of the modeling processes as possible (Wood et al. 2015), from data collection to noting waterbirds' behavior, which is particularly invaluable when the driver is very sitespecific. Models are a simplification of the real world and so decisions will also need to be made as to what parameters to leave in or out and the sensitivity of the model to these. Embedding stakeholders in the process also allows them to test scenarios, thus increasing their confidence and acceptance in the methods and to adjust their management response (Wood et al. 2018). For example, stakeholders from industry, government, and conservation charities were involved in data input, testing conservation strategies for shellfisheries management (Burry Inlet, Stillman et al. 2001, West et al. 2003b; Burry Inlet/Three Rivers, Stillman 2008c, Stillman et al. 2010; Solway Firth, Stillman 2008a, Stillman and Wood 2013a; The Wash-A, Stillman et al. 2003, Goss-Custard et al. 2004; Menai Straits, West and McGrorty 2003, Caldow et al. 2004; Morecambe Bay, West and Stillman 2010), building of power facilities (Bridgwater Bay, Garcia et al. 2016; Liverpool Bay, Kaiser et al. 2005), housing development (Southampton Water-B; Stillman et al. 2012), port development (Baie de Seine, dit Durell et al. 2005; Humber-A, Stillman et al. 2005b), and habitat loss (Southampton Water-A, Wood 2007; Cardiff Bay, Goss-Custard et al. 2006a).

\section{Data input collection and validity of outputs}

The waterbird IBMs are designed to reliably inform management or policy for these birds and their habitats, and so it is critical that the accuracy of their predictions is tested. A key part of this validation process is that the data used to test a model are independent from the data used to develop the model (e.g., using data at a similar site or generic information related to the species). Ideally, predictions at all of these levels of organization of the models should be tested to ensure that accurate impacts are being predicted from accurate underlying states (behavior) of individuals.

All case studies involved some degree of testing, in which model predictions were compared to observations or expectations. However, the ability to test different parts of the models depended on the availability of suitable data within each case study, and so not all tests could be conducted in all cases. Tests are particularly important for critical processes underlying survival within the model. For instance, a key process is the proportion of time birds spend feeding, which Stillman and Goss-Custard (2010) found that the IBMs tended to predict relatively accurately. This is important as it is a measure of the overall level of difficulty birds are having meeting their energy requirements, and so it is a key test to assess the suitability of the models for informing policy and management. Thus, ensuring key processes are accurately represented is extremely important.

The waterbird IBMs were often used to predict the consequences of novel, future environmental change at a site but could only be tested for present or past environmental conditions (as the future condition did not yet exist). There therefore needed to be confidence that the assumptions and processes within the models would hold for the new environmental conditions for which predictions were required. This is achieved through one of the key central assumptions of these IBMs, based on evolutionary principles that the basis from which behavioral decisions are made-fitness maximization-will not change, no matter how much the environment does. A further assumption is that the basic physiology of the birds does not change, for example, the range of food types that can potentially be consumed and the way in which energy 
requirements is determined by environmental conditions. The model birds are therefore expected to respond to novel environmental change in the same ways that real birds would.

\section{Informing management response}

The recommended management response for the case studies described was determined by whether singular or concurrent drivers of a certain magnitude affected the ability of birds to survive or emigrate. Some drivers had greater impacts than others, or did not have an adverse effect on the birds. For example, the presence of some potential tidal lagoons in Severn EstuaryA (Bournemouth University 2010), or some offshore wind farms in Liverpool Bay (Kaiser et al. 2005) were not predicted to negatively impact shorebirds or common scoter Melanitta nigra, respectively. The reason in these cases was that the developments were in locations that contained relatively little food for the birds and so were not important feeding areas. In contrast, the same case studies predicted that other tidal barrage or wind farm options that did occupy important feeding areas could have a negative impact on the birds. In the absence of evidence of an impact, conservation often proceeds on the basis of the precautionary principle, which can mean that activities that have no negative effect on the birds can be banned. Evidence provided by the waterbird IBMs made it possible to distinguish potentially damaging activities from those that did not have an effect, so allowing developments or management options to be ordered in terms of their impact on the birds.

Similarly, waterbird IBMs have predicted the magnitude of harvesting activities, that can remove food consumed by birds or disturb the birds, that can occur without adversely affecting the birds (e.g., greater activity leading to increased energetic requirements which could lead to a decline in mass unless greater food is provided, ultimately resulting in death. Thresholds of when this occurs are dependent on individual situations and per species). Eighteen case studies used MORPH in relation to shellfisheries, for instance, setting shellfishery quotas to ensure that sufficient food remains for Eurasian Oystercatcher (e.g., The Wash-A, B, and C; Stillman et al. 2003, Goss-Custard et al. 2004, Caldow et al. 2007, West et al. 2007). This allowed the balance between conservation (i.e., what is the quantity of shellfish that can be harvested without adversely impacting the birds?) and commercial activities (i.e., how many shellfish can be harvested and when?) to be achieved for shellfishing industry and regulators, conservation charities, and government organizations. Answers depended on the initial amount of shellfish and the size of the bird population, both of which can vary year by year and between sites. For instance, in the Menai Straits (West and McGrorty 2003, Caldow et al. 2004), predictions included how Blue Mussel could be moved to different shore levels as they grow to minimize losses to oystercatcher and crabs without adversely affecting the birds. Exe Estuary-G (Goss-Custard et al. 2019) indicated how the shellfishing Blue Mussel harvest can be adapted throughout the non-breeding season (when birds are present), accounting for the decreasing food requirements of birds for the remainder of the season, to increase the overall harvest, again without adversely affecting oystercatcher. Finally, Burry Inlet/Three Rivers (Stillman 2008c, Stillman et al. 2010), The Wash-A (Caldow et al. 2003, Goss-Custard et al. 2004), and Baie de Somme-A (Goss-Custard et al. 2004) predicted the required quantity of shellfish for oystercatcher to survive the non-breeding season, hence the amount of shellfish that could potentially be harvested without adversely affecting the birds.

Individual-based models can incorporate environmental change that is beneficial for wildlife, as well as detrimental change, and some case studies demonstrated how mitigation measures could potentially offset any negative impacts of drivers. For example, Baie de Seine (dit Durell et al. 2005), Cardiff Bay (Goss-Custard et al. 2006a), and Southampton Water-A (Wood 2007) showed how the negative effects of habitat loss through industrial development could potentially be offset by creating new habitat that either increased the area or time available for feeding. In Strangford Lough (West et al. 2002), shellfishery management was mitigated for through proposed changes to fisheries (e.g., hand harvesting of cockles, rather than mechanical harvesting, timing of harvest). Individual-based models can therefore inform environmental management both by predicting the negative impacts 
of drivers and by predicting how these impacts can be reduced through a range of mitigation measures.

\section{The way forward}

The waterbird IBMs were usually designed to address the impact of drivers on a single site. In order to provide predictions that could usefully inform environmental management on a site, the models needed to accurately represent the environmental processes, behavioral, physiology, and fates of birds on the site, that is, the models were site-specific. The question that then arises is how can more general insights be determined from models that are, in most cases, restricted to single sites? This can be achieved by overviewing the predicted effect of specific drivers on a range of sites to understand reasons for variation in impacts between sites. For example, the threshold magnitude of a driver leading to negative impact could be predicted for a range of sites with different environmental characteristics and then the site characteristics associated with a lower or higher threshold determined. Although this approach could potentially be extended to any driver, to date most progress has been made in understanding the impact of shellfishing, especially the amount of food that needs to be reserved after shellfishing without adversely impacting on the survival of oystercatcher. The combined predictions of several case studies (e.g., Baie de Somme-A, Goss-Custard et al. 2004; Bangor Flats, Goss-Custard et al. 2004; Exe Estuary-B, Goss-Custard et al. 2004; and The Wash-A, Stillman et al. 2003, Goss-Custard et al. 2004) provide three general insights into the food requirements of these birds. First, more food needs to be reserved than the amount of food that the birds actually eat, because birds are unable to find all of the food, some birds are excluded from the food resources due to competition with others, and food is lost due to sources other than the birds themselves (Goss-Custard et al. 2004). Second, the relative amount of food that needs to be reserved depends on characteristics of a site, including whether the primary prey are Common Cockle Cerastoderma edule or Blue Mussel, for example, as the amount of competition between the birds differs between these prey species. These insights have supported policy changes in the Wadden Sea, Netherlands, and
The Wash that increases the amount of shellfish reserved for the birds, sites in which high mortality of oystercatcher occurred under previous policies of reserving less for the birds (GossCustard and Stillman 2008). Third, in many cases studies, the birds may have been able to cope with one potentially adverse change, but not two, threatening their ability to survive. This was particularly notable with multiple hazards, where cold weather increased birds' energetic requirements. This suggests that future modeling of anthropogenic environmental change on waterbird environments should take account of the most extreme weather conditions rather than average, so that the birds have the maximum ability to survive.

These examples demonstrate how general ecological insights can be obtained from site-specific IBMs, provided that the IBMs are applied to a wide enough range of sites. Inclusion of stakeholder data and expertise will further increase these benefits to enhance conservation efforts or waterbirds and other species.

\section{CONCLUSION}

The purpose of this paper was to encourage the wider use of Individual-based Models (IBMs) to inform environmental management, by overviewing lessons from the steps through which this has been achieved in waterbirds. The Drivers-Pressures-State-Impact-Response (DPSIR) framework provided a valuable way of comparing the different case studies, showing the place that IBMs occupied within the overall environmental management processes (linking pressures, through states to impacts). For instance, the use of DPSIR highlighted why there was a decreased or increased chance of survival through a range of drivers and pressures, thus gaining an improved understanding and better identification of mitigation needs. By applying the DPSIR framework to better understand the process of bird survival rather than traditionally focusing on the end result (i.e., whether birds will survive in light on environmental changes) it provides managers with a greater understanding of mitigation measures and how and why they should be applied. These enable a greater appreciation of sensitivities and when to intervene during processes of change. Furthermore, the use 
of IBMs also increased understanding of multiple sensitivities and concurrent drivers in the waterbirds' environment, such as timing of harvesting or adverse changes in weather. This is particularly important where cold weather is an additional threat (a multiple hazard) to another driver of change. Thus, future modeling may need to take greater account of the most extreme weather conditions to maximize survival.

There are particular characteristics of waterbird systems that make them especially suitable for IBMs, including their relative simplicity and ease of observation, the extent to which they have been researched, and the amount of existing data. Technological advances will mean that collecting suitable data from more complex systems should become more routine, but we would especially encourage the application of IBMs to systems that share some of the characteristics of the waterbird systems, especially where novel environment change is affecting these systems. The use of stakeholders in collecting such data and in framing IBMs is encouraged, allowing a better portrayal of the modeled system from those who observe and manage waterbirds in the field.

\section{ACKNOWLEDGMENTS}

The research program described in this paper has been developed in collaboration with many colleagues. Specifically, we would like to thank John Goss-Custard, Richard Caldow, Sarah Durell, Andy West, Selwyn McGrorty, Mick Yates, Roger Herbert, Kevin Wood, Kathryn Ross, Katharine Bowgen, Catherine Collop, Leo Clarke, Elli Rivers, and Lindsay Biermann for their valued contributions and assistance over the years.

\section{Literature Cited}

Atkinson, P. W., N. A. Clark, M. C. Bell, P. J. Dare, J. A. Clark, and P. L. Ireland. 2003. Changes in commercially fished shellfish stocks and shorebird populations in the Wash, England. Biological Conservation 114:127-141.

Atkinson, P. W., and R. A. Stillman. 2008. Carrying Capacity Modelling for the Pied Oystercatcher at Lauderdale and Surrounding Sites. Lauderdale Quay Proposal, British Trust for Ornithology, Norfolk, UK.

Bournemouth University. 2010. Severn tidal power Sea topic paper. Waterbirds. Annex 3 - Waterbird
Individual based modelling. Bournemouth University, Poole, UK.

Bournemouth University, and Wildfowl and Wetlands Trust. 2018. Wildfowl functionally linked land. ECM_48346. Individual based modelling approach. Wildfowl and Wetlands Trust, Slimbridge, UK.

Bowgen, K. M. 2016. Predicting the effect of environmental change on wading birds: insights from individual-based models. Dissertation. Bournemouth University in collaboration with HR, Wallingford, UK.

Bowgen, K. M., R. A. Stillman, and R. J. H. Herbert. 2015. Predicting the effect of invertebrate regime shifts on wading birds: insights from Poole Harbour, UK. Biological Conservation 186:60-68.

Caldow, R. W. G., H. A. Beadman, S. McGrorty, R. A. Stillman, J. D. Goss-Custard, S. E. A. 1. V. D. Durell, A. D. West, M. J. Kaiser, K. Mould, and A. Wilson. 2004. A behavior-based modeling approach to reducing shorebird-shellfish conflicts. Ecological Applications 14:1411-1427.

Caldow, R. W. G., R. A. Stillman, S. Durell, A. D. West, S. McGrorty, J. D. Goss-Custard, P. J. Wood, and J. Humphreys. 2007. Benefits to shorebirds from invasion of a non-native shellfish. Proceedings of the Royal Society B-Biological Sciences 274:14491455.

Caldow, R. W. G., R. A. Stillman, and A. West. 2003. Modelling study to determine the capacity of The Wash shellfish stocks to support eider Somateria mollissima. Centre of Ecology and Hydrology, Dorset, UK.

Clarke, L. J. 2018. Ecosystem impacts of intertidal invertebrate harvesting: from benthic habitats to bird predators. Dissertation. Bournemouth University, Poole, UK.

Clarke, R. T., and J. D. Goss-Custard. 1996. The Exe estuary oystercatcher-mussel model. Pages 390393 in J. D. Goss-Custard, editor. The oystercatcher: from individuals to populations. Oxford University Press, Oxford, UK.

Collop, C. 2016. Impact of human disturbance on coastal birds: population consequences derived from behavioural responses. Dissertation. Bournemouth University, Poole, UK.

Deville, A.-S. 2013. Besoins énergétiques et distribution spatiale du Flamant rose (Phoenicopterus roseus) dans les salins de Camargue, conséquences de la reconversion du site pour la conservation de l'espèce (Energetic needs and spatial distribution of the Greater Flamingo (Phoenicopterus roseus), salt pans reconversion consequences for the conservation of the species). Dissertation. Universite Montpellier II, Montpellier, France. 
dit Durell, S. E. A. L. V. 2007. Differential survival in adult Eurasian oystercatchers Haematopus ostralegus. Journal of Avian Biology 38:530-535.

dit Durell, S. E. A. L. V., R. A. Stillman, P. Triplet, C. Aulert, D. O. dit Biot, A. Bouchet, S. Duhamel, S. Mayot, and J. D. Goss-Custard. 2005. Modelling the efficacy of proposed mitigation areas for shorebirds: a case study on the Seine estuary, France. Biological Conservation 123:67-77.

dit Durell, S. E. A. L. V., R. A. Stillman, P. Triplet, M. Desprez, C. Fagot, N. Loquet, F. Sueur, and J. D. Goss-Custard. 2008. Using an individual-based model to inform estuary management in the Baie de Somme, France. Oryx 42:265-277.

Durell, S. E. A. L. V. D., R. A. Stillman, R. W. G. Caldow, S. McGrorty, A. D. West, and J. Humphreys. 2006. Modelling the effect of environmental change on shorebirds: a case study on Poole Harbour, UK. Biological Conservation 131:459-473.

Duriez, O., S. Bauer, A. Destin, J. Madsen, B. A. Nolet, R. A. Stillman, and M. Klaassen. 2009. What decision rules might pink-footed geese use to depart on migration? An individual-based model. Behavioral Ecology 20:560-569.

Environment Protection Agency. 1995. A conceptual framework to support development and use of environmental information in decision-making. Environmental Statistics and Information Division. Office of Policy, Planning and Evaluation (2163). EPA230-R-95-012.

Evans, M. R. 2012. Modelling ecological systems in a changing world. Philosophical Transactions of the Royal Society B: Biological Sciences 367:181190.

FEBI. 2013a. Fehmarnbelt Fixed Link Bird Services (FEBI). Fauna and Flora - Birds - Impact Assessment. Birds of the Fehmarnbelt Area. E3TR0015. DHI, Hørsholm, Denmark.

FEBI. 2013b. Fehmarnbelt Fixed Link EIA. Bird Investigations in Fehmarnbelt - Baseline. Volume II. Waterbirds in Fehmarnbelt. Report No. E3TR0011. DHI, Hørsholm, Denmark.

Gabrielsen, P., and P. Bosch. 2003. Environmental indicators: typology and use in reporting. European Environment Agency.

Garcia, C., R. A. Stillman, R. M. Forster, T. Silva, and J. Bremner. 2016. Nuclear power and coastal birds: predicting the ecological consequences of warmwater outflows. Ecological Modelling 342:60-81.

Goss-Custard, J. D., et al. 2006a. Test of a behaviorbased individual-based model: response of shorebird mortality to habitat loss. Ecological Applications 16:2215-2222.

Goss-Custard, J. D., P. Triplet, F. Sueur, and A. D. West. 2006b. Critical thresholds of disturbance by people and raptors in foraging wading birds. Biological Conservation 127:88-97.

Goss-Custard, J. D., et al. 2006c. Intake rates and the functional response in shorebirds (Charadriiformes) eating macro-invertebrates. Biological Reviews 81:501-529.

Goss-Custard, J. D., K. M. Bowgen, and R. A. Stillman. 2019. Increasing the harvest for mussels Mytilus edulis without harming oystercatchers Haematopus ostralegus. Marine Ecology Progress Series 612:101110.

Goss-Custard, J. D., R. W. G. Caldow, R. T. Clarke, S. E. A. L. V. dit Durell, and W. J. Sutherland. 1995a. Deriving population parameters from individual variations in foraging behaviour. I. Empirical game theory distribution model of oystercatchers Haematopus ostralegus feeding on Mussels mytilus edulis. Journal of Animal Ecology 64:265-276.

Goss-Custard, J. D., R. W. G. Caldow, R. T. Clarke, and A. D. West. 1995b. Deriving population parameters from individual variations in foraging behaviour. II. Model tests and population parameters. Journal of Animal Ecology 64:277-289.

Goss-Custard, J. D., and R. A. Stillman. 2008. Individual-based models and the management of shorebird populations. Natural Resource Modeling 21:3-71.

Goss-Custard, J. D., R. A. Stillman, A. D. West, R. W. G. Caldow, P. Triplet, S. E. A. L. V. dit Durell, and S. McGrorty. 2004. When enough is not enough: shorebirds and shellfishing. Proceedings of the Royal Society B: Biological Sciences 271:233-237.

Grimm, V., and S. F. Railsback. 2005. Individual-based modeling and ecology. Princeton University Press, Princeton, New Jersey, USA.

Herbert, R. J. H., C. J. Davies, K. M. Bowgen, J. Hatton, and R. A. Stillman. 2018. The importance of nonnative Pacific oyster reefs as supplementary feeding areas for coastal birds on estuary mudflats. Aquatic Conservation: Marine and Freshwater Ecosystems 28:1294-1307.

IPBES [Intergovernmental Science-Policy Platform on Biodiversity and Ecosystem Services]. 2019. Global assessment report on biodiversity and ecosystem services of the Intergovernmental Science-Policy Platform on Biodiversity and Ecosystem Services. IPBES Secretariat, Bonn, Germant.

Kaiser, M. J., A. Elliott, M. Galanidi, E. I. S. Rees, R. Caldow, R. Stillman, W. Sutherland, and D. Showler. 2005. Predicting the displacement of common scoter Melanitta nigra from benthic feeding areas due to offshore windfarms. University of Wales, Bangor, UK.

Nolet, B. A., A. Gyimesi, R. R. D. van Krimpen, W. F. de Boer, and R. A. Stillman. 2016. Predicting effects 
of water regime changes on waterbirds: insights from staging swans. PLOS ONE 11:e0147340.

Patrício, J., M. Elliott, K. Mazik, K.-N. Papadopoulou, and C. J. Smith. 2016. DPSIR-Two cecades of trying to develop a unifying framework for marine environmental management? Frontiers in Marine Science 3:1-14.

Pettifor, R. A., R. W. G. Caldow, J. M. Rowcliffe, J. D. Goss-Custard, J. M. Black, K. H. Hodder, A. I. Houston, A. Lang, and J. Webb. 2000. Spatially explicit, individual-based, behavioural models of the annual cycle of two migratory goose populations. Journal of Applied Ecology 37:103-135.

Ross, K. E. 2013. Investigating the physical and ecological drivers of change in a coastal ecosystem: from individual-to population-scale impacts. Dissertation. Bournemouth University, Poole, UK.

Stillman, R. A., et al. 2001. Predicting shorebird mortality and population size under different regimes of shellfishery management. Journal of Applied Ecology 38:857-868.

Stillman, R. A., et al. 2003. An individual behaviourbased model can predict shorebird mortality using routinely collected shellfishery data. Journal of Applied Ecology 40:1090-1101.

Stillman, R. A., et al. 2005a. Coastal bird diversity. Maintaining migratory coastal bird diversity: management through individual-based predictive population modelling. Centre for Ecology and Hydrology, Winfrith Newburgh, UK.

Stillman, R. A., A. D. West, J. D. Goss-Custard, S. McGrorty, N. J. Frost, D. J. Morrisey, A. J. Kenny, and A. L. Drewitt. 2005b. Predicting site quality for shorebird communities: a case study on the Humber estuary, UK. Marine Ecology Progress Series 305:203-217.

Stillman, R. A., A. D. West, S. E. A. V. Dit Durell, W. R,. G. Caldow, S. McGrorty, M. G. Yates, R. A. Garbutt, T. J. Yates, W. E. Rispin, and N. J. Frost. 2005c. Estuary Special Protection Areas - Establishing baseline targets for shorebirds. Centre for Ecology and Hydrology, Dorchester, UK.

Stillman, R. 2008a. Predicted effect of shellfishing on the oystercatcher and knot populations of the Solway Firth. Bournemouth University, Poole, UK.

Stillman, R. A. 2008b. MORPH - An individual-based model to predict the effect of environmental change on foraging animal populations. Ecological Modelling 216:265-276.

Stillman, R. A. 2008c. Predicting the effect of shellfish stocks on the oystercatcher and knot populations of the Burry Inlet and Three Rivers. Countryside Council for Wales Marine Monitoring Report No. 65. Bournemouth University for the Countryside Council for Wales, Poole, UK.
Stillman, R. A., and J. D. Goss-Custard. 2010. Individual-based ecology of coastal birds. Biological Reviews 85:413-434.

Stillman, R. A., J. D. Goss-Custard, A. D. West, S. E. A. L. V. D. Durell, R. W. G. Caldow, S. Mcgrorty, and R. T. Clarke. 2000. Predicting mortality in novel environments: tests and sensitivity of a behaviour-based model. Journal of Applied Ecology 37:564-588.

Stillman, R. A., J. D. Goss-Custard, and K. A. Wood. 2014. Predicting the mussel food requirements of oystercatchers in the Exe Estuary. Bournemouth University/Natural England, Bournemouth/Exeter, UK.

Stillman, R. A., J. J. Moore, A. P. Woolmer, M. D. Murphy, P. Walkere, K. R. Vanstaen, D. Palmer, and W. G. Sanderson. 2010. Assessing waterbird conservation objectives: an example for the Burry Inlet, UK. Biological Conservation 143:2617-2630.

Stillman, R. A., A. E. Poole, J. D. Goss-Custard, W. G. C. Richard, M. G. Yates, and P. Triplet. 2002. Predicting the strength of interference more quickly using behaviour-based models. Journal of Animal Ecology 71:532-541.

Stillman, R. A., S. F. Railsback, J. Giske, U. Berger, and V. Grimm. 2015a. Making predictions in a changing world: the benefits of individual-based ecology. BioScience 65:140-150.

Stillman, R. A., K. A. Wood, W. Gilkerson, E. Elkinton, J. M. Black, D. H. Ward, and M. Petrie. 2015b. Predicting effects of environmental change on a migratory herbivore. Ecosphere 6:114.

Stillman, R. A., E. M. Rivers, W. Gilkerson, K. A. Wood, B. A. Nolet, P. Clausen, H. M. Wilson, and D. H. Ward. 2021. Predicting impacts of food competition, climate and disturbance on a longdistance migratory herbivore. Ecosphere 12:e03405.

Stillman, R. A., A. D. West, R. T. Clarke, and D. Liley. 2012. Solent Disturbance and Mitigation Project Phase II. Predicting the impact of human disturbance on overwintering birds in the Solent. Solent Forum, Bournemouth, UK.

Stillman, R. A., and K. A. Wood. 2013a. Predicting food requirements of overwintering shorebird populations on the Solway Firth. A report to Scottish Natural Heritage and Marine Scotland. Bournemouth University, Poole, UK.

Stillman, R. A., and K. A. Wood. 2013b. Predicting oystercatcher food requirements on the Dee Estuary. A report to Natural Resources Wales. Bournemouth University, Poole, UK.

Toral, G. M., R. A. Stillman, S. Santoro, and J. Figuerola. 2012. The importance of rice fields for glossy ibis (Plegadis falcinellus): management recommendations derived from an individual-based model. Biological Conservation 148:19-27. 
van Roomen, M., C. van Turnhout, E. van Winden, B. Koks, P. Goedhart, M. Leopold, and C. Smit. 2005. Trends in benthivorous waterbirds in the Dutch Wadden Sea 1975-2002: large differences between shellfish-eaters and worm-eaters. Limosa 78:21-38.

West, A. D., J. D. Goss-Custard, S. McGrorty, R. A. Stillman, S. Durell, B. Stewart, P. Walker, D. W. Palmer, and P. J. Coates. 2003a. The Burry shellfishery and oystercatchers: using a behaviour-based model to advise on shellfishery management policy. Marine Ecology Progress Series 248:279-292.

West, A. D., J. D. Goss-Custard, S. McGrorty, R. A. Stillman, S. L. V. dit Durell, B. Stewart, P. Walker, D. W. Palmer, and P. J. Coates. 2003b. The Burry shellfishery and oystercatchers using a behaviourbased model to advise on shellfishery management policy. Marine Ecology Progress Series 248:279292.

West, A. D., and S. McGrorty. 2003. Marine monitoring project: modelling osytercatchers and their food on the Dee Estuary, Traeth Lafan and Burry Inlet Spa to inform target setting and site management. Centre of Ecology and Hydrology, Dorchester, UK.

West, A., and R. Stillman. 2010. A single year study to determine the capacity of Morecambe Bay European marine site to support oystercatcher, using shellfish resource modelling techniques. Bournemouth University, Bournemouth, UK.

West, A. D., R. A. Stillman, and A. Portig. 2002. Modelling of the interaction between oystercatchers and shellfish in Strangford Lough, Northern Ireland. Centre for Ecology and Hydrology, Dorset, UK.

West, A. D., M. G. Yates, S. McGrorty, and R. A. Stillman. 2007. Predicting site quality for shorebird communities: a case study on the Wash embayment, UK. Ecological Modelling 202:527-539.

Wood, K. A., and R. A. Stillman. 2014. Do birds of a feather flock together? Comparing habitat preferences of piscivorous waterbirds in a lowland river catchment. Hydrobiologia 738:87-95.

Wood, K. A., R. A. Stillman, and J. D. Goss-Custard. 2015. Co-creation of individual-based models by practitioners and modellers to inform environmental decision-making. Journal of Applied Ecology 52:810-815.

Wood, K. A., R. A. Stillman, and G. M. Hilton. 2018. Conservation in a changing world needs predictive models. Animal Conservation 21:87-88.

Wood, P. J. 2007. Human impacts on coastal bird populations in the Solent. Dissertation. University of Southampton, Southampton, UK.

\section{SUPPORTING INFORMATION}

Additional Supporting Information may be found online at: http://onlinelibrary.wiley.com/doi/10.1002/ecs2. 3632/full 